\title{
Molecular detection and evaluation of resistance of Mycoplasma Pneumoniae to macrolide (Erythromycin) due to mutation in the 23S rRNA gene among Iranian Patients with respiratory infections
}

\section{Mohammad Niakan}

Shahed University Faculty of Medical Sciences

\section{Susan Rostampur}

Tehran University of Medical Sciences

\section{Reza Mirnejad}

Baqiyatallah University of Medical Sciences

\section{Mehrdad Halaji}

Isfahan University of Medical Sciences

Iman Pouladi ( $\square$ imanpouladi96a@gmail.com )

https://orcid.org/0000-0002-0640-2727

\section{Research note}

Keywords: Mycoplasma pneumoniae, Macrolide resistance, Erythromycin, 23S rRNA gene

Posted Date: April 8th, 2020

DOI: https://doi.org/10.21203/rs.3.rs-17763/v1

License: (c) (1) This work is licensed under a Creative Commons Attribution 4.0 International License. Read Full License 


\section{Abstract}

Objective: Mycoplasma pneumoniae is a common cause of community-acquired pneumonia. The global increased resistance of $M$. pneumoniae strains to macrolide (ML) has become a worrisome health problem. The widespread use of these drugs has led to increased rate of reported ML-resistant $M$. pneumoniae (MRMP) throughout the world. Therefore, this study was aimed to evaluate the resistance of M. pneumoniae against erythromycin due to mutations in the $23 S$ rRNA gene of patients with respiratory infections in Iran.

Results: According to the findings of the present study, employing specific primers showed that 17 cases (17\%) were positive for mycoplasma genus and 6 cases (6\%) positive for M. pneumoniae species. Also, analysis of the sequence of $23 S$ rRNA gene, revealed that one of the samples had mutations at positions A2431G and G2491A. Measuring the minimum inhibitory concentration (MIC), revealed that all samples positive for M. pneumoniae with 23S rRNA gene were sensitive to erythromycin, and no ML resistance was reported.

\section{Introduction}

Mycoplasma pneumoniae (M. pneumoniae) is one of the common causes of upper and lower respiratory tract infections, and is a major cause of community-acquired pneumonia (CAP) and atypical pneumonia which is responsible for mortality and morbidity among children and adults (1-4). Since M. pneumoniae lacks cell wall, the infection is primarily treated with macrolide antibiotics (MLs), tetracycline, and fluoroquinolones (5-7). Macrolides like erythromycin, azithromycin and clarithromycin are commonly considered as the first-line treatment of $M$. pneumoniae infections, because alternative antibiotics, such as tetracycline and fluoroquinolones have side effects $(8,9)$. In addition to antimicrobial activity against $M$. pneumoniae, MLs have anti-inflammatory effects against $M$. pneumoniae infections, and are pharmacologically inhibitors of cytokines, particularly IL-8 $(10,11)$. Because of limited therapeutic options, the global increase in resistance of $M$. pneumoniae to MLs is a major health concern worldwide. Moreover, the widespread application of these drugs has led to elevated rate of ML-resistant $M$. pneumoniae (MRMP) throughout the world $(7,12,13)$. MRMP infection has been shown to cause prolonged treatment, persistent cough, and an elevated time of fever reduction compared with those infections sensitive to treatment $(14,15)$. Currently, the MRMP has been reported more than $90 \%$ in Asia and $26 \%$ in the Europe $(7,8,16)$. Undoubtedly, the emergence of MRMP is a serious health threat due to the widespread use of macrolide antibiotics in the treatment of $M$. pneumoniae infections, especially in Asia in recent years. Thus, it has attracted the attention of many scientists (13). The mechanism of resistance of $M$. pneumoniae to $M L$ antibiotics has been as a point mutation (nucleotide displacement) of domain $\mathrm{V}$ in certain positions in $23 S$ rRNA gene of $\operatorname{MRMP}(17,18)$. In recent years, a number of previous studies, exposed strains of $M$. pneumoniae strains to macrolides, and proposed that all strains with resistance mutations displayed high levels of resistance to $\mathrm{ML}$ antibiotics in broth dilution experiments. After Specific Primer-Polymerase Chain Reaction (SSP-PCR) and analysis of the sequences of domain $\mathrm{V}$ of the 23Sr RNA gene in some positions, such as A2063G, A2064G, and A2064C, a series of 
A-to-G or A-to-G nucleotide displacements were identified. Therefore, resistance to MLs in M. pneumoniae can occur due to point mutations in the $23 S \operatorname{rRNA}$ gene $(10,17,19)$. Therefore, this study was aimed to evaluate the resistance of $M$. pneumoniae against erythromycin due to mutations in the $23 S$ rRNA gene of patients with respiratory infections in Iran.

\section{Methods}

In this study, 100 samples of throat swab were collected from patients with atypical pneumonia referring to Mostafa Khomeini and KhatamolAnbiah hospitals in Tehran province in 2018. For sampling, individuals diagnosed with clinical symptoms of respiratory infections by a lung specialist, such as weakness, lethargy, fatigue, persistent headache and dry cough, shortness of breath, sputum production, muscle pain, and no antibiotic use during the past month were targeted for recruitment. Samples were stored in transport pleuropneumonia-like organisms (PPLO) broth medium were obtained from Merck (Germany) to transfer them to the laboratory. In the laboratory, $1 \mathrm{ml}$ of the transport medium was transferred following passing through the $0.45 \mu \mathrm{m}$ filter in the main Glucose PPLO broth medium, containing $20 \%$ horse serum, $0.3 \%$ yeast extract, . $3 \%$ meat extract, $0.33 \mathrm{ml}$ penicillin, $0.5 \mathrm{ml}$ polymyxin $\mathrm{B}$, and $0.5 \mathrm{ml}$ amphotericin $\mathrm{B}$ in $5-10 \% \mathrm{CO}$, and were then incubated at $35^{\circ} \mathrm{C}$ for 3 weeks. In this study, the standard strain was M. pneumoniae (ATCC: 29342) which was developed from the Molecular Biology Research Center of Baqiyatallah University of Medical Sciences. The kit was obtained from Roche Co. (Germany) was used to extract DNA from the Glucose PPLO broth medium in which clinical specimens were cultured and incubated at $37^{\circ} \mathrm{C}$ for 3 weeks in $5-10 \% \mathrm{CO} 2$. After extraction of DNA samples, specific primers were used to identify Mycoplasma genus (16S rRNA gene) and M. pneumoniae strain ( $P 1$ gene) as shown in Table 1.

Table-1: primers sequences used in this study

\begin{tabular}{|llll|}
\hline Gene & $\begin{array}{l}\text { Primer } \\
\text { Sequence }\end{array}$ & & $\begin{array}{l}\text { Product Size (bp) } \\
\text { Reference }\end{array}$ \\
\hline $16 S$ & GP01 & F primer: 5' 'ACTCCTACGGGAGGCAGCAGT-3' $^{\prime}$ & $713 \mathrm{~b}(20)$ \\
$r R N A$ & MGSO & R primer : 5' & $450 \mathrm{bp}(20)$ \\
$P 1$ & MPPIF & TGCACCATCTGTCACTCTGTTAACCTC-3' & $793 \mathrm{bp} \mathrm{(21)}$ \\
$23 S$ & MPPIR & F primer: 5'-AAAGGAAGCTGACTCCGACA-3' & \\
$r R N A$ & Mp-F1 & R primer: 5'-TGGCCTTGCGCTACTAAGTT-3' & \\
& Mp-R1 & Mp-F1: 5'-TAACTATAACGGTCCTAAGG - 3' & \\
& & Mp-R1: 5'- CGCTACAACTGGAGCATAAGA-3' & \\
\hline
\end{tabular}

The PCR reaction was performed at final concentration of $25 \mu$ including an initial denaturation at $94{ }^{\circ} \mathrm{C}$ for $5 \mathrm{~min}, 35$ cycles comprised of denaturation at $94^{\circ} \mathrm{C}$ for 35 seconds, primer binding to the target DNA at $56^{\circ} \mathrm{C}$ for 40 seconds, elongation at $72{ }^{\circ} \mathrm{C}$ for 45 seconds, as well as a final elongation at $72^{\circ} \mathrm{C}$ for 5 minutes, according to the protocol, for M. pneumoniae, and also another PCR reaction at final concentration of $25 \mu \mathrm{l}$, including an initial denaturation at $94^{\circ} \mathrm{C}$ for $4 \mathrm{~min}, 33$ cycles comprised of denaturation at $94^{\circ} \mathrm{C}$ for 45 seconds, primer binding to the target DNA at $55^{\circ} \mathrm{C}$ for 45 seconds, 
elongation at $72{ }^{\circ} \mathrm{C}$ for 50 seconds, as well as a final elongation at $72^{\circ} \mathrm{C}$ for 5 minutes, according to the protocol for the 23S rRNA gene. The PCR products (ATCC: 29342) were finally electrophoresed. Finally, the PCR products positive for $23 S r R N A$ gene were sequenced to detect mutations of domain $\mathrm{V}$ in $23 S \mathrm{~S} R \mathrm{NA}$ gene of MRMP, and sequences of 23S rRNA gene were analyzed. In order to prepare samples positive for P1 gene of M. pneumonia, the MIC was carried out by micro-dilution of Glucose PPLO broth containing $25 \%$ horse serum, $0.3 \%$ yeast extract, and $0.3 \%$ meat extract in 96 wells of microplates, after preparation of antibiotic macrolide suspension (erythromycin). Then, the microplates prepared for microscopic specimens were incubated for $5-6$ days at $37^{\circ} \mathrm{C}$. Next, the MIC for erythromycin was determined based on color changes of Glucose PPLO broth enriched with horse serum, yeast extract, and meat extract. Glucose PPLO broth is a phenol red (a PH indicator) medium and $M$. pneumoniae growth causes the color of the medium to change from original purple to yellow.

\section{Results}

The present study recruited 100 patients with respiratory infections, of whom 48 (48\%) were males and $52(52 \%)$ were females. The average age of the participants was 53.62 years, ranging from 17 years to 85 years. According to the findings of our study, 14 subjects (14\%) had M. pneumoniae colonies grown on PPLO agar. Figure 1 (A-B) indicates samples tested with SSP-PCR with specific primers of $M$. pneumoniae. The length of $16 S$ rRNA gene fragment of Mycoplasma strain is about $713 \mathrm{bp}$. Of 100 examined samples obtained from electrophoresis, this fragment was observed in the standard strain in 17 samples (17\%). Also, among specimens positive for PCR, the 450 bp DNA fragment of $P 1$ gene was found in our standard strain among 6 subjects using P1-specific primer of M. pneumoniae. According to the results of the PCR test, 6 cases $(6 \%)$ were infected with M. pneumoniae. Figure 1 (C), illustrates the electrophoretic evaluation of 23S rRNA in samples positive for M. pneumoniae infection. Using the $23 S$ rRNA-specific primer, the 793 bp fragment was observed in the standard (ATCC: 29342) strain in 6 samples.

Analysis of the $23 S$ rRNA gene sequence, revealed that only one of the samples had point mutation at A2431G and G2491A positions. Measuring the MIC in all samples positive for M. pneumoniae using broth micro-dilution method, showed that all specimens were sensitive to erythromycin. Moreover, no ML resistance was reported (Table 2). Therefore, mutations in domain $\mathrm{V}$ of $23 S$ rRNA gene at $\mathrm{A} 2431 \mathrm{G}$ and G2491A were not associated with resistance of $M$. pneumoniae against erythromycin. 
Table 2

MIC ranges $(\mu \mathrm{g} / \mathrm{ml})$ for Erythromycin antimicrobial against $M$. pneumonia.

\begin{tabular}{|llll|}
\hline Clinical isolate & $\begin{array}{l}\text { Antimicrobial } \\
\text { Agent }\end{array}$ & MIC & Mutation \\
\hline 1 & Erythromycin & $0 / 0039$ & NO \\
2 & Erythromycin & $0 / 0039$ & Yes \\
3 & Erythromycin & $0 / 0156$ & NO \\
4 & Erythromycin & $0 / 0078$ & NO \\
\hline 5 & Erythromycin & $0 / 0039$ & NO \\
\hline 6 & Erythromycin & $0 / 0156$ & NO \\
\hline $\begin{array}{l}\text { Reference strain } \\
\text { ATCC: } 29342\end{array}$ & Erythromycin & 0.0039 & NO \\
$\begin{array}{l}\text { MIC range } \\
\text { for all isolates }\end{array}$ & Erythromycin & $0.0039-0.0156$ & \\
\hline
\end{tabular}

\section{Discussion}

Pneumonia caused by $M$. pneumoniae is a self-limiting illness, occurring by direct damage of the lung airways and inflammatory response (22). Lucier et al. reported a number of ML-resistance $M$. pneumoniae each at different positions in the $\mathrm{V}$ domain of the 23S rRNA gene (2063 and 2064) with displacement of A-G, which appeared following exposure to erythromycin $(10,17)$. The prevalence of MRMP follows a diverse pattern in different countries, which is attributed to the excessive use of macrolides and age of the patients (12). ML resistance is associated with a point mutation in domain $\mathrm{V}$ of $23 S$ rRNA gene and ribosomal proteins L22 and L14. Mutation affecting 23S rRNA gene at A2063G position is the most common mutation, followed by $\mathrm{A} 2064 \mathrm{G}$ position, which is mostly responsible for significant ML resistance in $M$. pneumoniae $(10,23)$. Results of the analysis of the sequence of $23 S$ rRNA gene showed that point mutations at $\mathrm{A} 2431 \mathrm{G}$ and $\mathrm{G} 2491 \mathrm{~A}$ positions were reported only in one specimen. In addition, the broth microdilution MIC method revealed that all samples positive for M. pneumoniae, were sensitive to erythromycin, and no ML resistance was reported in specimens. The rate of MRMP among study participants was $0.6 \%, 0 \%$. The prevalence of MRMP was reported as $2 \%, 50 / 1$ in Switzerland, 1.5\%, 87.1\%, 202/176 in Japan, 97\%, 33/32 in China, 1.2\%, 167/2 in Germany, and 9.8\%, 51/5 in France (7). Brown and colleagues conducted a study in England (2015), and reported mutations associated with $\mathrm{ML}$ resistance in samples positive for $M$. pneumoniae. They found that 43 samples of the total 60 specimens positive for M. pneumoniae had mutations in domain $\mathrm{V}$ of $23 S$ rRNA gene, with $\mathrm{ML}$ resistance in four specimens (9.3\%), which was not consistent with the results of our study (23). Haruki and colleagues investigated hospitalized children in Japan (2014) and detected 33 cases of $M$. 
pneumoniae by PCR, of which 31 isolates were resistant to macrolide, and all isolates displayed point mutation at 2063 and 2064 in domain V of 23S rRNA, which was not in accordance with the present study. This difference in the results of these two studies may be due to the older age of the patients in our study (24). Liu and colleagues (2014) examined 580 samples of throat swab suspected for $M$. pneumoniae, and reported that 70 cases were resistant to erythromycin. They also revealed point mutation at 2063 and 2064 in domain V of 23SrRNA in all specimens positive for M. pneumoniae, which was not in accordance with our study (21). Zhou et al. (2015) also examined 650 samples of throat swab, and used PCR method. All sequences of the domain $V$ of the 23SrRNA were investigated. They showed that 100 percent $(71 / 71)$ of $M$. pneumoniae isolated from patients with (CAP) were resistant to erythromycin, clarithromycin, and azithromycin. In addition, all ML-resistant strains of M. pneumoniae had point mutation at $\mathrm{A} 2063 \mathrm{G}$ in the domain $\mathrm{V}$ of $23 S$ rRNA (25), which was not consistent with the results of our study, and it can be attributed to the larger sample size of this study. This was one of the first studys conducted in Iran. Results of the analysis of the sequence of the 23S rRNA gene, showed that only one strain displayed point mutations at A2431G and G2491A. The broth microdilution MIC showed that all specimens positive for M. pneumoniae were resistant to erythromycin, and no ML resistance was observed. Besides, all point mutations affecting domain V of 23S rRNA at A2431G and G2491A were not associated with $M L$ resistance to erythromycin. In conclusion, in order to control the emergence of $M L$ resistance among M. pneumoniae strains, the use of these antibiotics should be restricted in Iran and reduce the widespread use.

\section{Limitations}

Non-application and evaluation of other macrolide group antibiotic resistance in the study can be mentioned as one of the main limitations of the present study.

\section{Declarations}

\section{Ethics approval and consent to participate}

Administrative or ethical permissions were required to use the patient swabs.

(IR.SHAHED.REC.1397. 039). The study protocol was approved by the Department of Medical Microbiology, Faculty of Medicine, Shahed University, Tehran, Iran The study used bacteria isolated from clinical samples in the clinical microbiology laboratory.

\section{Consent for publication}

Not applicable 
Availability of data and materials

The datasets used and/or analyzed during the current study are available from the corresponding author on reasonable request.

\section{Competing interests}

The authors declare that they have no competing interests.

\section{Funding}

This study was supported by Department of Medical Microbiology, Faculty of Medicine, Shahed University, Tehran, Iran.

\section{Authors' contributions}

MN, RM, conceived, designed and supervised the study and MI revised the manuscript; SR, MH, and MI: collected and analyzed the data and drafted the manuscript. All authors read and approved the fnal manuscript.

\section{Abbreviations}

ML:macrolide, PPLO: pleuropneumonia-like organisms; PCR: polymerase chain reaction; MIC:minimum inhibitory concentration, MRMP: ML-resistant M. pneumoniae .

\section{Acknowledgment}

The results described in this paper were part of a thesis. This study was approved by the ethics committee of Shahed University of Medical Sciences, Tehran, Iran (IR.Shahed). The authors would like to thank all staff members of the Department of Microbiology of Shahed University of Medical sciences.

\section{References}

1. Eshaghi A, Memari N, Tang P, Olsha R, Farrell DJ, Low DE, et al. Macrolide-resistant Mycoplasma pneumoniae in humans, Ontario, Canada, 2010-2011. Emerg Infect Dis. 2013; 19(9).

2. Dash S, Chaudhry R, Dhawan B, Dey AB, Kabra SK, Das BK. Clinical spectrum and diagnostic yields of Mycoplasma pneumoniae as a causative agent of community-acquired pneumonia. Journal of Laboratory Physicians. 2018;10(1):44-9.

3. Gdalevich M, Haas EJ, Dukhan L, Katz M, Zelenski V, Moran-Gilad J. Control of a Mycoplasma pneumoniae Outbreak in an Institutional Setting Using Azithromycin Prophylaxis. Front Public 
Health. 2017;5:366.

4. Ranjbar R, Halaji M. Epidemiology of Mycoplasma pneumoniae prevalence in Iranian patients: a systematic review and meta-analysis. Medical Microbiology, 2019.

5. Kawai Y, Miyashita N, Kubo M, Akaike H, Kato A, Nishizawa Y, et al. Nationwide Surveillance of Macrolide-Resistant Mycoplasma pneumoniae Infection in Pediatric Patients. Antimicrob Agents Chemother. 2013;57(8):4046-9.

6. Nakatani M, Shingo Mizunaga S, Takahata M, Nomura N. Inhibitory activity of garenoxacin against DNA gyrase of Mycoplasma pneumonia. J Antimicrob Chemother. 2012;67:1850-2.

7. Meyer Sauteura P, Bleischa B, Voitb A, Maurerb F, Rellya C, Berger C, et al. Survey of macrolideresistant Mycoplasma pneumoniae in children with community-acquired pneumonia in Switzerland. Swiss Med Wkly. 2014;144:14041.

8. Spuesens E, Meijer A, Bierschenk D, Hoogenboezem T, Donker G, Hartwig N, et al. Macrolide Resistance Determination and Molecular Typing of Mycoplasma pneumoniae in Respiratory Specimens Collected between 1997 and 2008 in The Netherlands. J Clin Microbiol. 2012;50(6):1999-2004.

9. Yin YD, Wang R, Zhuo C, Wang H, Wang MG, Xie CM, et al. Macrolide-resistant Mycoplasma pneumoniae prevalence and clinical aspects in adult patients with community-acquired pneumonia in China: a prospective multicenter surveillance study. J Thorac Dis. 2017;9(10):3774-81.

10. Hong JH, Chun JK, Uh Y, Oh KJ, Kim J, Yoon KJ. Two Cases of Mycoplasma pneumoniae Pneumonia with A2063G Mutation in the 23S rRNA Gene in Siblings. Ann Lab Med. 2013;33:65-8.

11. Lee KE, Kim KW, Hong JY, Kim KE, Sohn MH. Modulation of IL 8 boosted by Mycoplasma pneumoniae lysate in human airway epithelial cells. J Clin Immunol. 2013;33:1117-25.

12. Meyer Sauteur P, Unger W, Nadal D, Berger C, Vink C, Rossum A. Infection with and Carriage of Mycoplasma pneumoniae in Children. Front Microbiol. 2016;7:329.

13. Zhao F, Liu G, Wu J, Cao B, Tao X, He L, et al. Surveillance of Macrolide-Resistant Mycoplasma pneumoniae in Beijing, China, from 2008 to 2012. Antimicrob Agents Chemother. 2013;57(3):15213.

14. Izumikawa K, Izumikawa K, Takazono T, Kosai K, Morinaga Y, Nakamura S, et al. Clinical features, risk factors and treatment of fulminant Mycoplasma pneumoniae pneumonia: a review of the Japanese literature. J Infect Chemother. 2014;20:181-5.

15. Saraya T. Mycoplasma pneumoniae infection: Basics. J Gen FAM Med. 2017;18(3):118-25.

16. Chironna M, Sallustio A, Esposito S, Perulli M, Chinellato I, Di Bari C, et al. Emergence of macrolideresistant strains during an outbreak of Mycoplasma pneumoniae infections in children. J Antimicrob Chemother. 2011;66(4):734-7.

17. Lucier TS, Heitzman K, Liu SK, Hu PC, et al. Transition mutations in the $23 \mathrm{~S}$ rRNA of erythromycinresistant isolates of Mycoplasma pneumoniae. Antimicrob Agents Chemother. 1995;39(12):2770-3. 
18. Jun T, Qing D, Pei D, Yi L, Dan L, Yue J, et al. P1 gene of Mycoplasma pneumoniae in clinical isolates collected in Beijing in 2010 and relationship between genotyping and macrolide resistance. Chin Med J. 2013;126(20):3944-7.

19. Liu Y, Ye X, Zhang H, Xu X, Li W, Zhu D ,et al. Antimicrobial Susceptibility of Mycoplasma pneumoniae Isolates and Molecular Analysis of Macrolide-Resistant Strains from Shanghai, China. American Society for Microbiology. 2009: 2160-2162.

20. Golmohammadi R, Ataee RA, Alishiri GH, Mirnejad R, Najafı A, Tate M, et al. Molecular Diagnosis of Mycoplasma pneumoniae in Synovial Fluid of Rheumatoid Arthritis Patients. Iran J Med Microbial. 2014;8(1):1-8.

21. Liu X, Jiang Y, Chen X, Li J, Shi D, Xin D. Drug Resistance Mechanisms of Mycoplasma pneumoniae to Macrolide Antibiotics. Biomed Res Int. 2014;2014:1-7.

22. Babaei Z, Pouladi I, Ashtari A, Azimi G, Niakan M. The Prevalence of Atypical Pneumonia Caused by Mycoplasma pneumoniae (P1 gene) in Patients with Respiratory Infections by Culture and Molecular PCR Methods in Tehran, Iran. Jundishapur Microbiol. 2020;12(11):e84174.

23. Brown RJ, Macfarlane-Smith L, Phillips S, Chalker VJ, et al. Detection of macrolide resistant Mycoplasma pneumoniae in England, September 2014 to September 2015. Euro Surveil. 2015;20(48):30078.

24. Haruki K, Tomoyuki T, Ayano I, Tsuyoshi S, Tomoo F. Characteristics of hospitalized children infected with macrolide-resistant. Mycoplasma pneumoniae brazj infectdis. 2014;18(3):294-9.

25. Zhou Z, Li X, Chen X, Luo F, Pan C, Zheng X, et al. Macrolide-Resistant Mycoplasma pneumoniae in Adults in Zhejiang, China.Journals(AAC) .2015;(2):1048-1051.

\section{Figures}




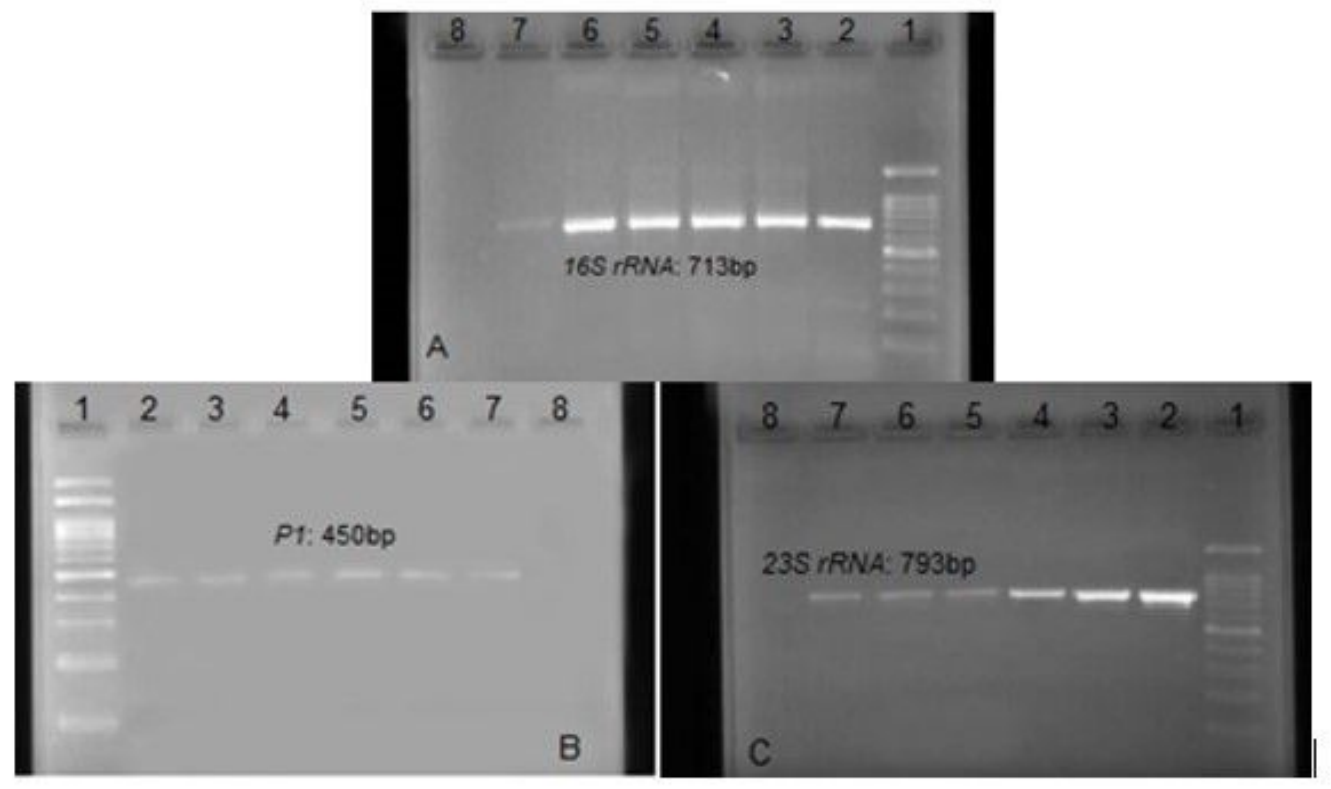

\section{Figure 1}

A) PCR amplification of the 16S rRNA gene. Lane 1: Ladder (100 bp), lane 8: negative control, lane 2: positive control (ATCC: 29342-713bp); lane 3-7: positive results. B) PCR amplification of the P1 gene. Lane 1: Ladder (100 bp), lane 8: negative control, lane 2: positive control (450bp); lane 3-7: positive results. C) PCR amplification of the 23S rRNA gene. Lane 1: Ladder (100 bp), lane 8: negative control, lane 2: positive control (793bp); lane 3-5, 6, and 7: positive results. 